\title{
Assessing of channel roughness and temperature variations on wastewater quality parameters using numerical modeling
}

\section{${ }^{*}{ }^{1}$ AMIR GHOLIPOUR; EBRAHIM ALAMATIAN ${ }^{2}$, NISHA FOERSTNER ${ }^{3}$}

\author{
Master science of wastewater engineering, Khavaran institute of higher education, Mashhad, Iran \\ Amirgh.civil@yahoo.com \\ Tel: +9805137664553, Mobile: +989152468960 , Fax: +9805135230690 \\ Assistant professor, Khavaran institute of higher education, Mashhad, Iran \\ Alamatian@khi.ac.ir ; Tel: +9805135230690, Mobile +989155149601 \\ Bachelor of Environmental Studies, University of Waterloo, Ontario, Canada \\ Vancouvernisha9@gmail.com; Tel:6047863735
}

KEYWORDS: channel roughness, wastewater, temperature, QUAL2K, BOD, DO

\begin{abstract}
Nowadays, problems and barriers to supply adequate water and address environmental issues have caused wastewater treatment (WWT) to be considered a high priority. In light of high costs of WWT, using natural capacities to reduce pollution could be potentially economically significant. In this paper, the impact of varying temperature and channel roughness has been investigated on the wastewater quality parameters using the QUAL2K (Q2K) Numerical Model. The results show, as temperature increases, the reduction rate of Biochemical Oxygen Demand (BOD) is more than the Chemical Oxygen Demand (COD). Also, organic nitrogen $(\mathrm{ON})$, organic phosphorus $(\mathrm{P})$, coliforms, total organic carbon (C), total suspended solids (TSS) and total nitrogen (TN) decrease; but nitrate concentration $\left(\mathrm{NO}_{3}\right)$ increases. This numerical assessment indicates that the purification rate is greater as temperature rises above $30^{\circ} \mathrm{C}$. The results show that by increasing channel roughness, BOD, COD, Particle Organic Matter (POM), organic nitrogen, phosphorus and coliforms have descending trends while inorganic phosphorus and ammonium concentrations have ascending trends. According to the obtained results, nitrate $\left(\mathrm{NO}_{3}\right)$ has a decreasing trend when the Manning Roughness Coefficient $(\mathrm{N})$ is higher than 0.04 along the channel, but is reduced when " $\mathrm{N}$ " is less than 0.04. (C) JASEM

http://dx.doi.org/10.4314/jasem.v19i1.16
\end{abstract}

\section{Introduction}

Wastewater generated by human activities has become a challenging issue. Human health is threatened by wastewater discharge into environment. Development produces industrial effluent that requires sewage excretion into the sewer network. But these units must consider initial standards in order to discharge their industrial effluent into the sewer network by setting up pre-treatment units. In most cases, many are not sufficiently equipped due to the lack of knowledgeable design and implementation costs. Lack of proper wastewater treatment plants (WWTPs) causes abundant environmental problems (Manap and Voulvoulis, 2015). On the other hand, constructing the required installation needs enormous investments to treat sewage. In this light, methods, which maximize the existing natural environment systems, thereby having low expenditures, mitigate the impacts of pollution right away. Using naturebased systems and combining them with purposeful management, can reduce contaminates with minimum costs (Vlachopoulou et al., 2014).

Evaluating the environmental impacts of pollution purification has been paid close attention to by researchers (Bertinelli et al., 2008; Navarro-Ortega et al., 2015). Consequently, the field investigations are expensive thus affording the use of models that simulate the natural environment circumstances and assist in predicting the approaches of purifying pollutants that should have priority. Khorasani and Fereidoun have used the QUAL2K (Q2K) mathematical model to assess the water quality of Qareso River in Kermanshah in Iran (2013). Strong correlation between the results of numerical modeling with experiment data is shown. Q2K is capable of predicting the effects of environmental parameters on pollution purification. European countries have been committed to abide by water quality instruction approved by urban wastewater treatment in the Summaries of EU Legislation (2007).

For example, the Olt River is exposed to the inlet of Covasna effluent in Romania. In order to reach desirable water quality, the pollution modeling in this river used QUAL2E (Q2E) by Petrescu et al (2011). The results demonstrated that best methods came from a three-pronged approach controlling environmental input, monitoring water quality and assessment modeling done contemporaneously. The Q2E water quality model was analyzed and calibrated using a series of field measurements of real data in extreme high temperature conditions (summer) by Drolcand and Zagorc (2007). The model has been done in order to estimate the effect of discharging domestic and industrial wastewater on dissolved 
oxygen (DO) concentration in Covasna. The results showed that in order to conform to the standards of Slovenia, BOD concentration should be less than 30 milligrams per liter before being discharged to the river.

Concrete is commonly used to construct wastewater channels. Over time, some factors such as abrasion, weathering, porous concrete, corrosion and algae growth in sewer channels cause variation in the concrete channels' roughness. In some cases, to mitigate environmental impacts, natural channels with herbaceous cover or, a combination of the natural and concrete channels are used. On the other hand, channel roughness methods used to carry wastewater vary greatly. Channel roughness calculations include wastewater hydraulic processes, depth of wastage channels and the flow of transmission velocity. Choosing the appropriate channel roughness method depends on simplifying the hydraulic and wastewater treatment processes. Plant growth and the Manning Roughness Coefficient results were studied in the channels for six months by Shih and Rahi (1981). In this study, the roughness changed from 0.094 to 0.613 . The roughness effect of hydraulic characteristics was assessed. The results showed roughness increased with growing plants. In addition, the $\mathrm{N}$ values and vegetation density were similarly related. The increase in $\mathrm{N}$ value was directly proportional to square root of vegetation density and two-thirds $(2 / 3)$ the power of flow depth in all types of vegetation. Channel roughness is influenced by the amount of wastewater dissolved oxygen (DO). The impacts of roughed up channels were investigated as boulders and other meso-scale obstructions were introduced. The flow increased significantly the complexity of the local flow patterns in their vicinity (Cokgo and Kucukali, 2005). Some of these patterns, such as vortex formation, higher turbulence intensity and local transitions from subcritical to supercritical and back to subcritical flow, seem to contribute to increased activity in terms of air entrainment; especially in the wake region of the obstruction. The number of boulders, their location and arrangement within the stream, as well as their height in relation to the flow depth are all-important factors to consider. Water depth was an important parameter for oxygen efficiency and distribution around the boulders. When the boulders got submerged, there was no oxygen gain in the system. Submerged boulders versus those protruding through the free surface (in addition to bed roughness) are expected to influence the ability of the flow to increase DO levels (Cokgo and Kucukali, 2004). In the literature, numerous constructed arrangements such as weirs, gates, cascades and chutes were designated for water re-aeration (Avery and Novak 1978; Nakasone 1987; Kim; Walters 2001). A study has been performed on DO values in streams and conducts which contained wastewater by Brain (2001). In this paper, DO influence on wastewater purification was determined. Also, a mathematical model of DO loss has been run, (Misra et al., 2005). The model analyzed oxygen behavior in water and its effect on chemical parameters.

The studies up to now have mostly focused on water quality in rivers from the effects of domestic and industrial sewages inputs or channel roughness in relation to hydraulics. These investigations have not assessed the effects of parameter variations such as temperature and re-aeration on sewage refinement approaches. Contamination can be reduced by increasing wastewater temperatures (Gillian Burger and Wayne Parker 2013; Wojnarowicz et al., 2013) . On the other hand, there are suitable regions where consistent numbers of sunny days naturally provide the desirable opportunity to refine wastewater. This paper's aim is to recommend analyzing the effects of temperature variations and channel roughness on the wastewater. Q2K will be utilized in the numerical modeling. The initial wastewater quality parameters are obtained from Parkand Abad WWTP.

\section{MATERIALS AND METHODS -}

Q2K model: $\mathrm{Q} 2 \mathrm{~K}$ have been presented by Tufts University in the United States (U.S.) to Simulate Rivers and Streams Water Quality (Chapra et al., 2008). One-dimensional modeling is performed in steady state hydraulics by Q2K. It uses three equations to calculate depth, flow, and velocity, all which include the Manning equation, weirs and rating curves. Q2K accommodates anoxia by reducing oxidation reactions to zero at low oxygen levels. In addition, de-nitrification is modeled as a first-order reaction that becomes pronounced at low oxygen concentrations. A generic pathogen is simulated. Pathogen removal is determined as a function of temperature, light and settling. Both alkalinity and total inorganic carbon are simulated. The river's $\mathrm{pH}$ is then computed based on these two quantities. The temperature variations effects and atmosphere are simulated on a daily scale. Q2K heat balance is taken for an element, and in the balance, the effluence of the adjacent elements which are located closely to each other, inflow, outflow, atmosphere and sediments effect are simulated (Chapra et al., 2008).

The modeling information: The modeling characters are chosen with regards to Parkand Abad WWTP statistics in Iran. In order to be sure that the numerical modeling results are correct, validation of applying Q2K has been done with Kannel's data (Kannel et al., 2007). The results correlated with Kannel's performance. The model includes an open rectangular concrete channel: $10 \mathrm{~km}$ long, 5 meters wide; and, 2 percent longitudinal slope.

Table 1 presents inlet wastewater quality to the channel. The discharge is $178 \times 10^{3}$ liters per day. Parkand Abad WWTP is located at longitude 59.57 
and latitude 36.44 . It is assumed that the wastewater flow at $0.00 \mathrm{~km}$ does not have any oxygen for the temperature modeling. There is not any input or output flow along the channel. The simulation has been modified for six different temperatures $(\mathrm{T})$ in order to assess the effect of temperature variations on wastewater purification. In the first case, the flow temperature is $23 \mathrm{C}^{0}$ and atmospheric temperature is applied on the first summer's day during the 24 hours (called Tv case). The meteorological data used is presented in Table 2. The amount of solar radiation in WWTP's surroundings is presented in Table 3. The wind speed is $2 \mathrm{~m} / \mathrm{s}$ and the cloud cover is set to zero. Temperature increases up to $50 \mathrm{C}^{0}$ have been applied in $10 C^{0}$ increments. In this case, the surrounding periphery and sewage temperature have been assumed to be constant, and equal to 10, 20, 30, 40 and $50 \mathrm{C}^{0}$ (called T10 ‘T20 ‘T30 ‘T40 and T50 cases, respectively). It is to be noted that when using solar swimming ponds, temperature can exceed $50 \mathrm{C}^{0}$ (Jaefarzadeh, 2005).

The Manning roughness coefficients (N) were investigated, and six $\mathrm{N}$ were adopted: $0.012,0.02$, $0.023,0.033,0.04$ and 0.05 . The chemical reactions were simulated in the model through the course of five days. In the end, the contaminations index was calculated with interpolation from the resulting values at the end of the each day. The solution method to estimate $\mathrm{PH}$ and its reaction come from Brent and Runge Kutta, respectively (Chapra and Canale, 2000). The Manning Equation is applied to evaluate hydraulic characteristics. It is assumed when the wastewater flow is released for the first time into the Channel, the initial conditions at standpoint of wastewater quality are not defined and therefore not included in the studies.
Table 1- The Initial Wastewater Quality Obtained from

Parkand Abad WWTP.

\begin{tabular}{|c|c|c|}
\hline & Index & Value \\
\hline $\mathrm{BOD}\left(\mathrm{mgo}_{2} / \mathrm{L}\right)$ & & 417 \\
\hline $\mathrm{COD}\left(\mathrm{mgo}_{2} / \mathrm{L}\right)$ & & 786 \\
\hline $\mathrm{NO} 3(\mathrm{mgN} / \mathrm{L})$ & & 6.1 \\
\hline c $\mathrm{P}(m g P / L)$ & & 6.18 \\
\hline $\mathrm{PH}$ & & 7.7 \\
\hline Coliform $(c f u / 100 \mathrm{~mL})$ & & 1500 \\
\hline $\mathrm{TKN}(\mathrm{mg} / \mathrm{L})$ & & 97 \\
\hline $\mathrm{TN}(\mathrm{mg} / \mathrm{L})$ & & 95.5 \\
\hline
\end{tabular}

Table 2- Temperature variations on First Summer's Day during the first 24 hours in Parkand Abad (The meteorology organization of the Khorasan Razavi 2013)

\begin{tabular}{cc}
\hline T (centigrade) & Time (Hour) \\
\hline 25.3 & 0 \\
29.2 & $3: 00$ \\
35.4 & $6: 00$ \\
38.8 & $9: 00$ \\
43.2 & $12: 00$ \\
39.8 & $15: 00$ \\
33.2 & $18: 00$ \\
28.8 & $21: 00$
\end{tabular}

Table 3- Daily Solar Radiation during (NOAA 2013).

\begin{tabular}{cc}
\hline $\begin{array}{c}\text { Solar radiation } \\
\text { (Watt per meter) }\end{array}$ & $\begin{array}{c}\text { Time } \\
\text { (Hour) }\end{array}$ \\
\hline 0 & 6 \\
11.2 & 7 \\
258 & 9 \\
525 & 11 \\
625 & 13 \\
571 & 15 \\
330 & 17 \\
51 & 19 \\
0.01 & 20
\end{tabular}

\section{RESULTS AND DISCUSSION}

The results of the numerical modeling are divided into two parts: sewage temperature variations and channel roughness. In the following, these effects on wastewater quality will be presented.

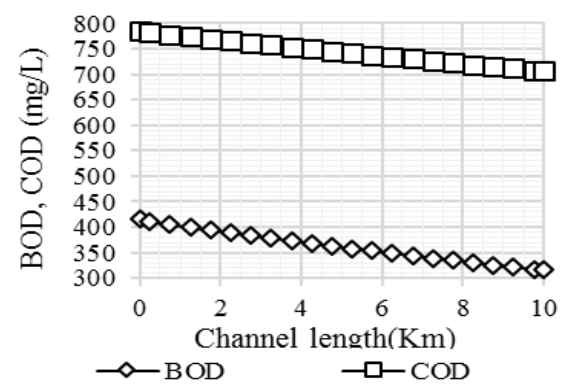

Fig 1- BOD and COD Variations along the
The Effect of Temperature Variations: The results of hydraulic modeling show that (What flow: maximum, ideal?) flow has been reached at the end of the channel after 0.11 day ( 2 hours and 38 minutes). Figure 1 indicates BOD and COD that belong to the existing situation (Tv). According to Table 1, BOD and COD concentrations are 417 and 786 milligram per liter in the channel entrance, respectively

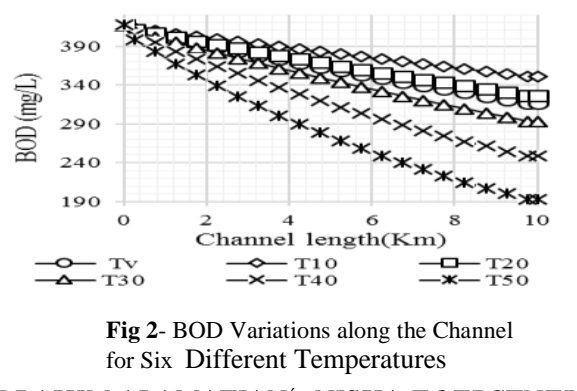

*IAMIR GHOLIPOUR; EBRAHIM ALAMATIAN ${ }^{2}$, NISHA FOERSTNER ${ }^{3}$ 
It is observed that BOD and COD decrease permanently along the channel. It seems that the BOD reducing slope is higher than the COD. Where BOD drops 24 percent to $317 \mathrm{mg} / \mathrm{L}$ at the end of the channel and COD drops $9.92 \%$ for a total of 708 $\mathrm{mg} / \mathrm{L}$. Figure 2 contains the six temperature variations used for BOD measurements along the channel.

Figure 2 demonstrates that BOD is reduced along the channel in all cases. But the overall BOD descent slope is higher with higher temperature. BOD reached 193 milligram per liter with a 54 percent descent at the end of the channel in the 50 degree centigrade. However, with only 10 centigrade, BOD decreased 16 percentage points to $351 \mathrm{mg} / \mathrm{L}$. So the results show that BOD decreases with increased temperature. The results of this paper show that by increasing the temperature from 10 to 50 centigrade, the BOD index was reduced by 38 percent along the studied channel.

Figure 3 shows COD in six temperatures along the channel. In all cases, COD decreased along the channel the further it travelled and the greater the temperature.

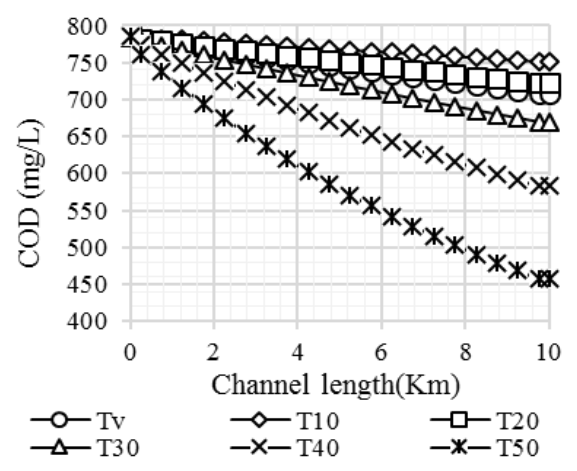

Fig 3- COD Six Variations of Temperature along the Channel.

Decreasing rate of both BOD and COD are expedited by increasing temperature (Figure 4).

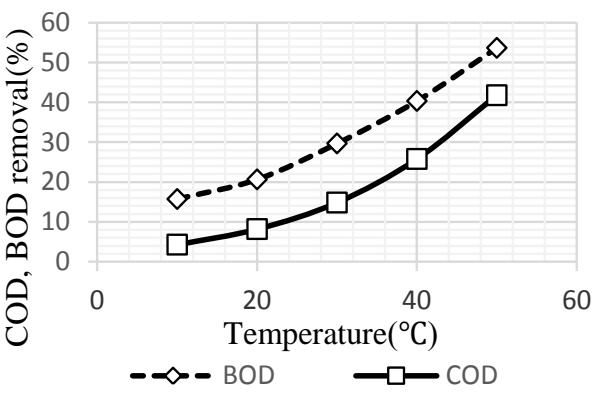

Fig 4- BOD, COD removal in temperature variations.

According to Figure 4, increasing the temperature from 10 to 50 degrees Centigrade caused COD to decrease 37.49 percent. It is observed in Figure4 that BOD and COD removal is not linear with increasing temperature but almost exponential.

Figure 5 shows the nitrate $\left(\mathrm{NO}_{3}\right)$ variations along the channel in different temperatures. It is observed that up to 40 degrees Centigrade, $\mathrm{NO}_{3}$ concentration increases gently but after 40 , the slope becomes dramatically steep. Meanwhile the initial nitrate value of $6.1 \mathrm{mg} / \mathrm{L}$ reaches $9.14 \mathrm{mg} / \mathrm{L}$ in 50 degrees

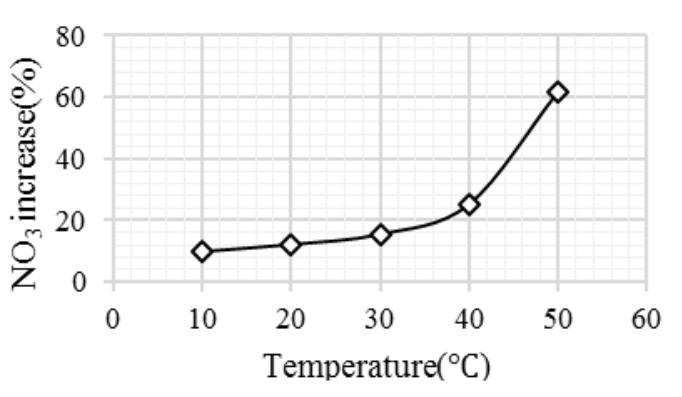

Fig 5- COD Increase in Temperature Variations.

Centigrade. According to the Iranian sewage outlet standards, this is lower than the maximum allowable limits required in order to discharge underground $(10 \mathrm{mg} / \mathrm{L})$ and surface $(50 \mathrm{mg} / \mathrm{L})$ water.

Figures 6 and 7 present removal percentages of organic nitrogen $(\mathrm{ON})$, organic phosphorus $(\mathrm{OP})$ total coliform (Tcoli), total organic carbon (TOC), total suspended solids (TSS) and total kajeldal nitrogen (TKN) in Temperature variations, respectively. It is to be noted that the whole values pertain to the end of the Channel. 


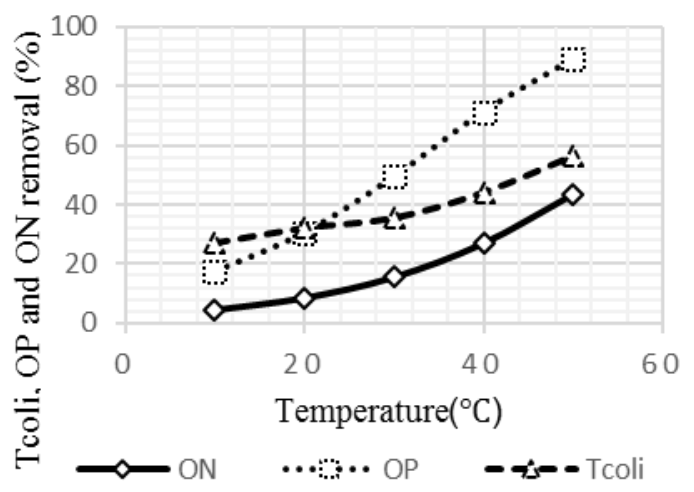

Fig 6- ON removal in Temperature Variations.

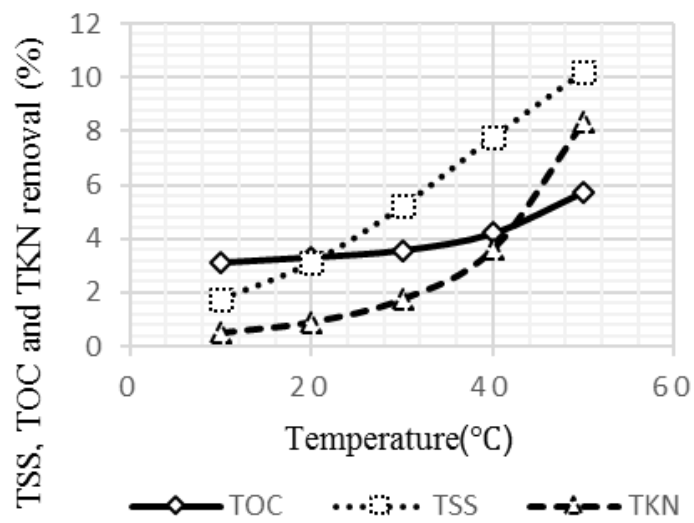

Fig 7- TSS, TOC and TKN removal in Temperature Variations.

It is observed that in all cases with increasing temperature, variation pace has also increased. ON, OP and Tcoli have shown a strong sensitivity to the temperature variations. As temperature increases to 50 degrees Centigrade more than half of the pollutants are removed. But TOC, TSS and TKN have less sensitivity towards temperature with only about a 6 percent reduction of their values. In Figures 6 and 7, where temperature is above 30 centigrade, the variation pace is much quicker.
Channel with Diverse Roughness: In this section, the Manning Roughness Coefficients and their effects on sewage quality are analyzed. According to Manning's Equation, it is obvious that with increased channel roughness, flow depth and retention time increase and velocity decreases. Retention time directly impacts dissolved oxygen concentration in wastewater. Figure 8 shows DO in six Manning Roughness Coefficients

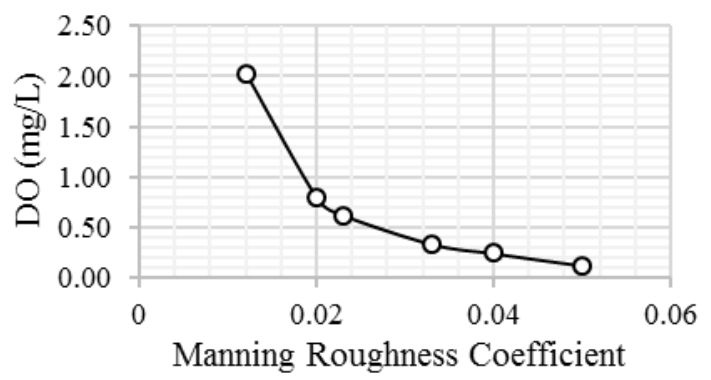

Fig 8- DO Manning Roughness Coefficients.

Figure 8 illustrates that DO is reduced by increasing channel roughness. Again, the curve is not linear and whenever roughness increases, the slope of the curve is diminished. DO is reduced by approximately 61 percent from 0.012 to 0.02 coefficients.
$\mathrm{NO} 3$ and $\mathrm{NH}_{4}$ in channel roughness are shown in Figures 9. 


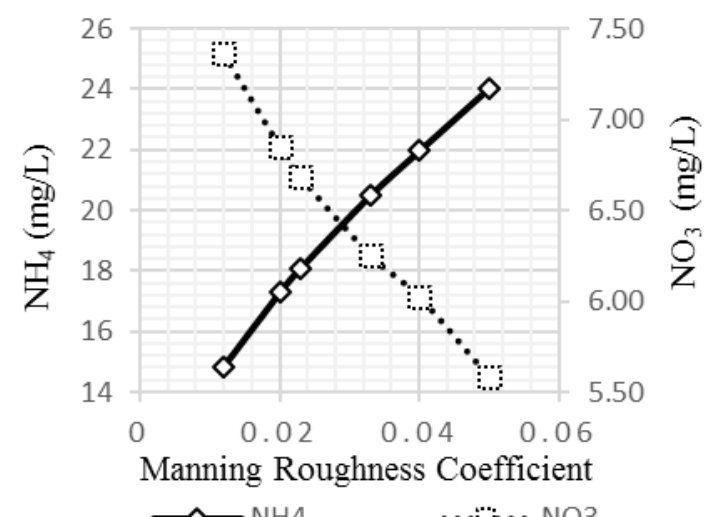

Fig 9- $\mathrm{NH}_{4}$ and $\mathrm{NO}_{3}$ in Manning Roughness Coefficients

Figure 9 shows a linearly rising curve along with uniform gradient. And, when channel roughness increases, $\mathrm{NH}_{4}$ has an accelerated rate. As the roughness changes from 0.012 to 0.05 , it has increased approximately 38 percent. As well, according to the following Figure $9, \mathrm{NO}_{3}$ reduces when channel roughness increases. Initial nitrate concentration is $6.1(\mathrm{mgN} / \mathrm{L})$ in 0.012 roughness, rising to 7.5 (mgN/L), resulting in an increasing value of 17 percent. However, the opposite is true when the roughness is 0.04 or higher, $\mathrm{NO}_{3}$ concentration decreases to $5.5(\mathrm{mg} / \mathrm{L})$ - a drop by $8.5 \%$. These Figures demonstrate that increasing channel roughness reduces both $\mathrm{NH} 4$ and NO3 concentrations.

Figure 10 shows the nitrate variations along the channel for different roughnesses.

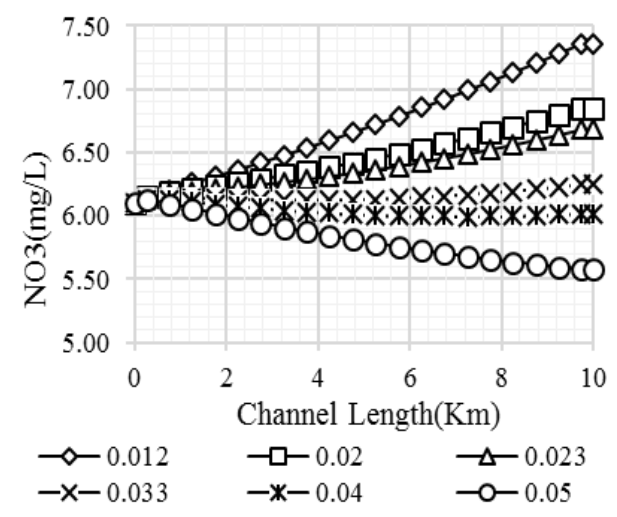

Fig 10- NO3 Variations in Manning Roughness Coefficients along the Channel.

Figure 10 indicates that the nitrate concentration is varied in diverse roughnesses. Roughnesses 0.04 and 0.05 have a descending rate but the other roughnesses show an ascending rate in 2 hours and 38 minutes.

Figure 11 shows the ON variations in Manning roughness coefficients.

According to Figure 11, increasing channel roughness decreases the $\mathrm{ON}$ concentration. In this regard, NO is

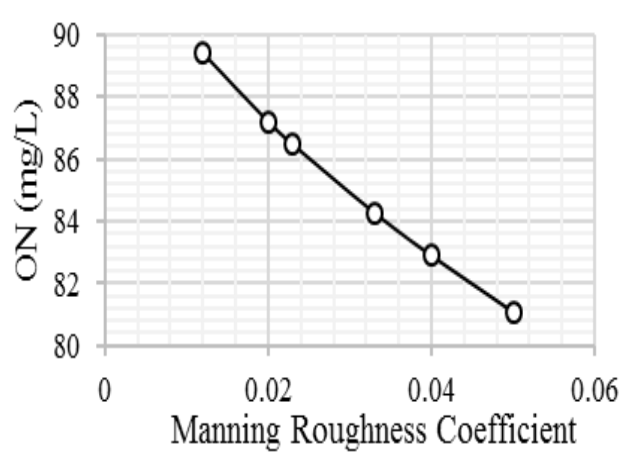

Fig 11- ON Variations in Manning Roughness Coefficients

reduced by 9 percent when roughness varied from 0.012 to 0.05 . It is observed that $\mathrm{ON}$ linearly descends with increasing channel roughness.

Figure 12 shows the BOD and COD concentrations in Manning Roughness Coefficients at the end of the channel $(10 \mathrm{Km})$. 


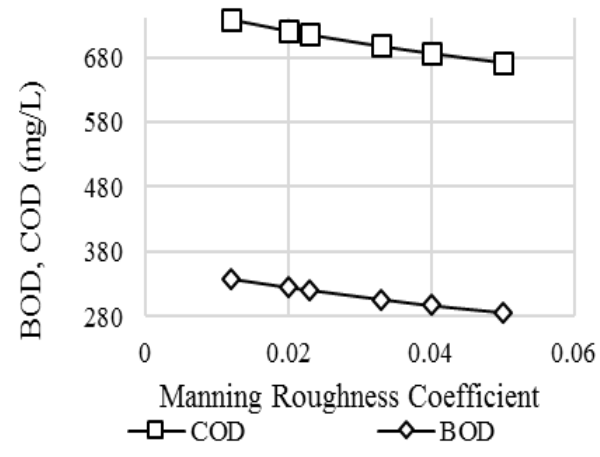

Fig 12- BOD and COD in Manning Roughness Coefficients Concentrations at the End of Channel.

Initial concentrations of BOD and COD are 417 and 876 respectively. Figure 12 demonstrates increased channel roughness decreases both COD and BOD. According to this figure, by increasing roughness, BOD and COD have decreased at the end of the channel. Increasing DO and Retention Time reduces BOD and COD. Thus, increased channel roughness results in longer Retention Time. Important to note is that Retention Time must increase up to a certain value of DO in order to react with BOD and COD. If there is no oxygen for consumption, the longer Retention Time is a mute variable.

Figures 13 represents organic phosphorous (OP) concentration in the Manning Roughness Coefficients.

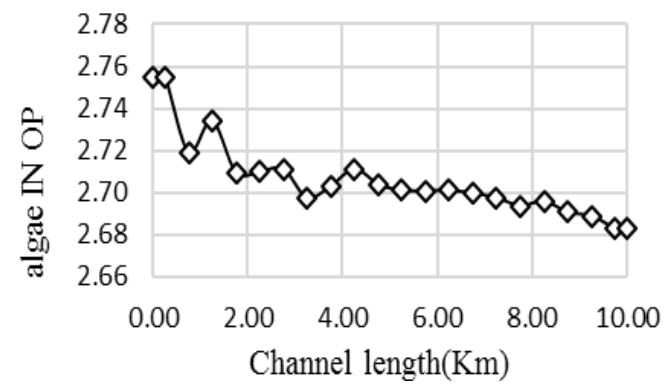

Fig 14- Algae IN OP along the Channel in Roughness 0.05

According to Figure 14, intracellular algae OP have a descending rate along the channel. There are some changes in amount of algae intracellular OP although these variations are not considered to be important.

Another factor influencing these parameters is solar radiation, which is not constant during the day. Also time and frequency of input throughout the day impacts the parameters being studied. Figure 15

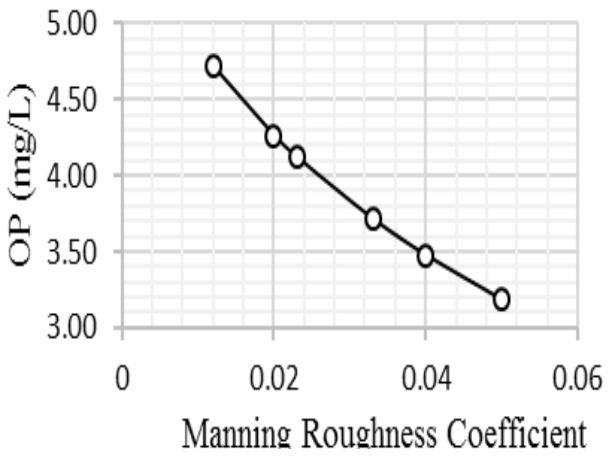

Fig 13- OP Variations in Manning Roughness Coefficients

In Figure 13, OP descends by increasing roughness. Here OP is reduced by $20 \%$ when the roughness ranges from 0.012 to 0.05 . This Figure shows that OP is reduced along the channel. This behavior demonstrates that the algae placed in the channel consume phosphorus. Algae grow well in phosphorous and nitrogen rich environments aided by the process of photosynthesis. During photosynthesis, plants take up $\mathrm{CO}_{2}$ and release oxygen. However, when algae die phosphorous becomes stored in their cells. Figure 14 shows algae intracellular OP (algae IN OP) along the channel in roughness 0.05 .

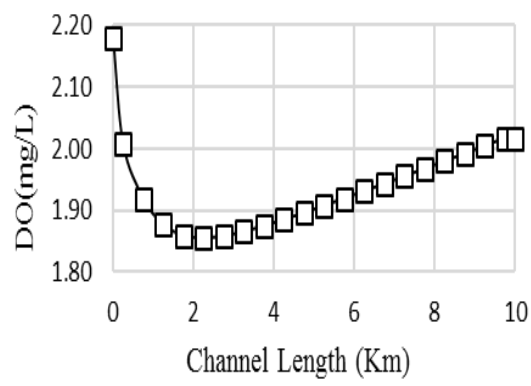

Fig15- DO along the Channel in Manning Roughness Coefficient 0.012

shows DO variations along the channel. The graph was plotted in a roughness coefficient of 0.012 .

Figure 15 illustrates DO is reduced in the inlet channel but, after about $2 \mathrm{~km}$ gradually increases. The result is due to vegetation cover area along the channel. Figure 16 shows Tcoli (cfu/100 mL) in channel roughness variations. 


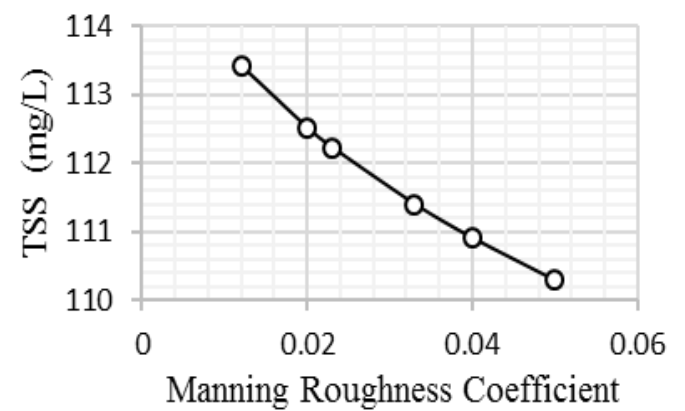

Fig 16- Total Coliforms in Manning Roughness Coefficien

According to Figure 16, increasing channel roughness reduces total coliforms. Removal rate are 27.4 and 37.2 percent respectively in the roughness of 0.012 and 0.05 respectively.

The remains of phytoplankton and algae in the water and wastewater created detritus or particulate organic matter (POM) (Chapra et al., 2008). The Particulate Organic Matter concentration depended on the temperature of the wastewater, its depth and velocity. Obviously, with the channel roughness variation, these three factors change and affect the amount of POM.

Figure 17 represents TSS concentrations in different roughnesses.

According to Figure 17, increasing roughness reduces the quantity of TSS, but not considerably.

Acknowledgements:The authors wish to acknowledge Mr. Majid. Daee for his contribution of wastewater quality data

Conclusion: In this study, temperature variations and channel roughness were assessed on the Parkand Abad wastewater treatment plant with the Wastewater Flow Model by Q2K Software.

At first, modeling was simulated for six different temperatures. At another stage, the Manning Roughness Coefficients were evaluated on some wastewater indexes. Findings include the following:

BOD and COD values are decreased as temperature increases. The decreasing rate of the BOD is more dramatic than the COD's descending rate. The results of studying parameters such as ON, OP, Tcoli, TOC, TSS and TKN show that these elements are reduced with increased temperatures. $\mathrm{NO}_{3}$ value increases mildly up to 40 degrees Centigrade steeply afterwards. Results show that aeration pace is not expedited after 30 degrees Centigrade. Numerical modeling demonstrated that increased Retention Time and

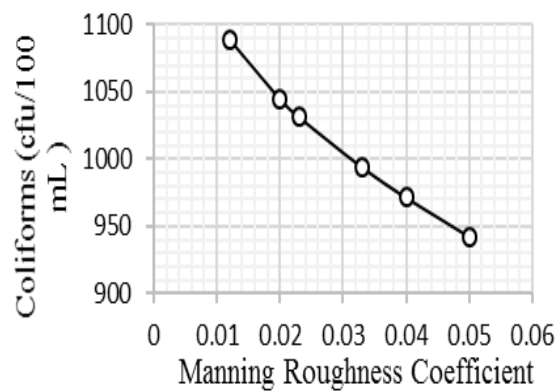

Fig 17- TSS in Manning Roughness Coefficients

decreased dissolved oxygen occurs through increased channel roughness. BOD, COD, POM,

ON, OP and Tcoli concentrations decreased with increased channel roughness. Concentrations of $\mathrm{NH}_{4}$ and inP increased with increased channel roughness but not significantly. $\mathrm{NO}_{3}$ and $\mathrm{DO}$ decreased in roughnesses above 0.04 along the channel. As oxygen diminished, $\mathrm{NO}_{3}$ also diminished (as an effect of the de-nitrification process).

Assessment of the algae behaviour along the channel showed that algae IN OP increases with increasing volume from the channel inlet as well as at the end of the channel. Algae growth rate increase despite dense herbaceous cover at the end of the channel, and DO is generated more by them. Also TSS decreases slightly by increasing channel roughness.

\section{REFERENCES}

Avery S T, Novak P (1978). Oxygen transfer at hydraulic structures. J. Hyd. Div. ASCE 104(11), 152-1540.

Brain O P G (2012). Dissolved Oxygen in Water, Streams and Watershed. B.F. Environmental Consultants Inc.

Bertinelli L, Strobl E, Zou B (2008). Economic Development and Environmental Quality: A Reassessment in Light of Nature's Selfregeneration Capacity. Science direct Volume 66 Issues $2-3$ pp 371-378.

Chapra S C, Pelletier G J, Tao H, (2008). QUAL2K: A Modeling Framework for Simulating River and Stream Water Quality, Version 2.11: Documentation and Users Manual; Department of Civil and Environmental Engineering, Tufts University: Medford, OR, USA.

Chapra S C, Canale R P (2000). Numerical Methods for Engineering, McGraw Hill. 
Cokgor S, Kucukali S (2005). Effect of Sediment Roughness on Surface Aeration around Boulders in an Open Channel Flow. RMZ- Material and Geoenvironment, Vol. 52, No. 1, 13-15.

Cokgor S, Kucukali S (2004). Oxygen Transfer in Flow around and over Stones Placed in a Laboratory Flume. Ecological Engineering, Elsevier, 23/3 205-212.

Drolcand A, Zagorc K J (2007). Calibration of QUAL2E Model for the Sava River (Slovenia). Water Sci. Techno 1, 40, 111-118.

Fereidoon M, Khorasani Gh. (2013). Water Quality Simulation in Qarresu River and the Role of Wastewater Treatment Plants in Reducing the Contaminants Concentrations. International Journal of Innovative Technology and Exploring Engineering (IJITEE), 3(5), 2278-3075.

Gillian Burger, Wayne Parker (2013). Investigation of the Impacts of Thermal Activated Sludge Pretreatment and Development of a Pretreatment Model, Water Research 47(14) pp 5245- 5256.

Jaefarzadeh M R (2005) Thermal Behaviour of a Large Salinity-gradient Solar Pond in the City of Mashhad, Iran. J. Sci. Technol. 29 (B2), 219229.

Kim J, Walters R W (2001) Oxygen Transfer at Low Drop Weirs. J. Env. Engrg. ASCE 127(7), 604610.

Kannel, P.R., Lee, S., Kanel, S.R., Lee, Y., Ahn, K.H., 2007.Application of QUAL2Kw for water quality modeling and dissolved oxygen control in the river Bagmati. Environ. Monit. Assess. 125, 201-217.

Misra A K, Peeyush C, Shukla J B (2005). Mathematical Modeling and Analysis of the Depletion of Dissolved Oxygen in Water Bodies. Nonlinear analysis: Real World Applications, 7, pp 980-996.

Manap N, Voulvoulis N (2015). Environmental management for dredging sediments - The requirement of developing nations, Journal of Environmental Management, Vol: 147, Pages: 338-348, ISSN: 0301-4797
Nakasone H (1987). Study of Aeration at Weirs and Cascades. J. Envir. Engrg. ASCE 113(1), 64-81.

National Oceanic and Atmospheric Administration (NOAA). 2013

Navarro-Ortega A, Acuna V, Bellin A et al (2015). Managing the effects of multiple stressors on aquatic ecosystems under water scarcity. The GLOBAQUA project, SCIENCE OF THE TOTAL ENVIRONMENT, Vol: 503, Pages: 3-9, ISSN: 0048-9697.

Petrescu V, Sumbasacu G, Nicolai S (2011). Monitoring and Mathematical Modeling Important Tools for Environmental Problems Environmental Engineering \& Management Journal (EEMJ) 10(11), 1779-1787.

Statistical meteorology data (2013). The meteorology organization in the City of Mashhad, Iran

Summaries of EU Legislation (2007).Urban Wastewater Treatment. European Commission

Shih S F, and Rahi G S (1981). Seasonal Variations of Manning's Roughness Coefficient in a Subtropical Marsh. TRANSACTIONS of the ASAE, Vol. 25, No. 1, pp. 116.119.

Vlachopoulou M, Coughlin D, Forrow D, Kirk S, Logan P, Voulvoulis Net al., (2014). The potential of using the Ecosystem Approach in the implementation of the EU Water Framework Directive, SCIENCE OF THE TOTAL ENVIRONMENT, Vol: 470, Pages: 684-694, ISSN: 0048-9697.

Wojnarowicz P., Ogunlaja O., Chen X et al (2013). Impact of Wastewater Treatment Configuration and Seasonal Conditions on Thyroid Hormone Disruption and Stress Effects in Rana catesbeiana Tailfin, Environmental Science \& Technology, 47, pp 13840-13847 